heterogeneous, but some review of the present state of knowledge would have been valuable.

Finally, lichenology in the British Isles is considered from various points of view in chapters 9,10 and 11 . The fact that chapter 10 could be written at all is an indication of the valuable work done by field lichenologists in the British Isles in recent years. It is unquestionably a most important paper and likely to become a classic, despite its preliminary nature. Those who have approach will perhaps find the authors' early comments (pp296-304) helpful and encouraging. The reviewers only slight reservation concerns the proposed status to be accorded to man-made communities and seral stages of successions (p302).

Chapter 9 is the first substantial paper to be published on lichen conservation and is an excellent blend of the scientific approach and commonsense. Two points seem to be worth emphasising. The 'capture' of important lichen communities in nature reserves does not necessarily ensure their safety, even from reserve management, where this is likely to be more related to the needs of other plant or animal populations, for example, birds (p417). Secondly, the use of transplanting to introduce or reintroduce lichens into seemingly suitable areas perhaps needs to be monitored (p428).

One other important contribution, chapter 2 , serves to emphasise the two major difficulties in lichen ecology, the problem of recognising the lichen species and that of defining the lichen an aversion to the phytosociological

microhabitat.

\section{Replacing animals in biomedical research}

Alternatives to Animal Experiments. By D. H. Smyth. Pp. 216. (Scolar Press: London, 1978.) Hardback £6; paperback $£ 2.90$.

SNATChed from a life of obscurity and installed in contemporary plastic palaces, cultured cells, the most widely claimed alternative to animal experiments, are in danger of becoming Pygmalion's protégés [with apologies to Elsdale \& Bard J. Cell Biol. 54, 626; 1972]. Whether cells lead primitive, less cultured lives when housed in more traditional residences is examined by Professor Smyth's book.

This book, written for the intelligent layman as well as the scientist, comprehensively surveys in an unemotional way the possibilities and limitations of cell culture as well as the many other methods suggested for replacing animals in biomedical research. As the
A few specific minor criticisms might be made, for example, about the statements on mineral nutrition of saxicolous lichens: "by dissolving silicates (lichen) hyphae can ... gain nutrients" (p33) and "An essential feature for colonization ... is the ability to accumulate nutrients from rain or run-off" (p34). It remains to be seen what is the case. About $p \mathrm{H}$ : the presence/ absence of lichens on leather, hair and wool is correlated with $p \mathrm{H}$ but not necessarily attributable to it directly (p257); $p \mathrm{H} 6.0$ is not more acid than pH 5.8 (p274). Also, it is implied that lichenin and isolichenin are the only important cell wall components in lichens (pp89 and 130) and that the digestion of lichens is likely to require quite different enzymes from those needed for fungal digestion (p110). Neither of the assertions need be true. And finally, there is the confusing use of terms such as competitive/aggressive (pp55 and 205), vagant/erratic (pp19 and 230) and eutrophication/hypertrophication (p287). The otherwise useful Selected Glossary does not help overmuch with regard to their correct usage.

The book is, however, something of a collection of papers and might have been better entitled "Aspects of Lichen Ecology". It is nevertheless a most worthwhile and valuable venture and will be an essential reference for workers in the field of lichen ecology.

B. W. Ferry

B. W. Ferry is Lecturer in Botany at Bedford College, University of London, $U K$.

\section{X-ray spectroscopy}

$X$-Ray Spectroscopy. Edited by H. K. Herglotz and L. S. Birks. Pp. 513. (Marcel Dekker: New York, 1978.) $\$ 49.50$.

$X$-Ray Spectroscopy is a collection of articles by various authors, and concentrates on the technique as a tool for chemical analysis. As with most multiple author books, it suffers from lack of continuity of style and content and the typescript presentation makes the comprehension of equations very difficult. Its use to scientists working in more fundamental fields such as atomic physics, plasma physics or astronomy and space physics is virtually zero.

The book is divided into two sections with eight or nine chapters in each. The first section, "Methods and Instruments", contains two or three chapters which may be considered as an introduction to the subject. These are, on the whole, well written chapters, but the limitations on their length leave a number of loose ends so that anyone wishing to find a thorough grounding in the field would find them disappointing. In most cases these points are developed later in the book, but there is no logical way in which the topic can be followed. For example, in chapter one there is a brief mention of crystal rocking curves in association with wavelength dispersion techniques. Just how these curves are obtained is described briefly in the chapter on chemical analysis, but one would only find this out by accident. One chapter worthy of mention in this section is on electron probe microanalysers which, apart from an inadequate description of some of the equations used, is a useful introduction to the subject.

The second section of the book, "Applications", contains chapters on a wide variety of subjects from geology to museum objects. On the whole, these chapters are interesting and very readable, but I suspect that specialists in these particular fields would be better advised to save their money and find a relevant review article. The short chapter on "X-ray Astronomy and Other Exotic Applications" is so brief and superficial that one wonders why it was included at all.

One reason why many people may buy this book, however, is for the very large number of references that it contains, but I found the book itself rather disappointing.

\section{T. A. Hall} periments.

Alan J. Paine

Alan J. Paine is a member of the $M R C$ Toxicology Unit, Carshalton, UK.
T. A. Hall is Lecturer in Physics at the University of Essex, Colchester, UK. 